\title{
Passive smoking and cardiorespiratory health in a general population in the west of Scotland
}

\author{
David J Hole, Charles R Gillis, Carol Chopra, Victor M Hawthorne
}

\begin{abstract}
Objective-To assess the risk of cardiorespiratory symptoms and mortality in non-smokers who were passively exposed to environmental smoke.

Design-Prospective study of cohort from general population first screened between 1972 and 1976 and followed up for an average of 11.5 years, with linkage of data from participants in the same household.

Setting-Renfrew and Paisley, adjacent burghs in urban west Scotland.

Subjects -15399 Men and women $(80 \%$ of all those aged 45-64 resident in Renfrew or Paisley) comprised the original cohort; 7997 attended for multiphasic screening with a cohabitee. Passive smoking and control groups were defined on the basis of a lifelong non-smoking index case and whether the cohabitee had ever smoked or never smoked.
\end{abstract}

Main outcome measure-Cardiorespiratory signs and symptoms and mortality.

Results-Each of the cardiorespiratory symptoms examined produced relative risks $>1 \cdot 0$ (though none were significant) for passive smokers compared with controls. Adjusted forced expiratory volume in one second was significantly lower in passive smokers than controls. All cause mortality was higher in passive smokers than controls (rate ratio $1.27(95 \%$ confidence interval 0.95 to 1.70$)$ ), as were all causes of death related to smoking (rate ratio $1.30(0.91$ to $1.85)$ ) and mortality from lung cancer (rate ratio 2.41 $(0.45$ to 12.83$)$ ) and ischaemic heart disease (rate ratio $2.01(1.21$ to $3 \cdot 35)$ ). When passive smokers were divided into high and low exposure groups on the basis of the amount smoked by their cohabitees those highly exposed had higher rates of symptoms and death.

Conclusion-Exposure to environmental tobacco smoke cannot be regarded as a safe involuntary habit.

\section{West of Scotland Cancer Surveillance Unit, Ruchill Hospital, Glasgow G20 9NB \\ David J Hole, MSC, statistician \\ Charles R Gillis, MD, director}

\section{Department of}

Epidemiology, School of Public Health, University of Michigan, Ann Arbor, Michigan, United States Carol Chopra, research student

Victor M Hawthorne, MD, professor

Correspondence and requests for reprints to: $\mathrm{Mr}$ Hole.

BrMed J 1989;299:423-7

\section{Introduction}

Though evidence has accumulated about the risk to health of involuntary, or passive, exposure to environmental tobacco smoke, further information is required from cohort studies to confirm these observations. Deleterious effects on the respiratory system of infants and children have been observed ${ }^{12}$ as have chronic effects on lung function in adults, ${ }^{3+}$ but these findings have been criticised on methodological grounds. An overview of 10 case-control and three cohort studies estimated a relative risk of 1.35 for lung cancer in people passively exposed compared with non-exposed controls. ${ }^{6}$ Three studies have reported increased (though not significant) risks of ischaemic heart disease in non-smokers with partners who smoke. ${ }^{789}$ Problems in interpreting these findings include lack of an objective measure of dose or exposure, failure to adjust for confounding variables, inappropriate methods of statistical analysis, and failure to measure other potentially important variables. ${ }^{10}$

This report is based on the Renfrew-Paisley survey, which was carried out in an area with a high incidence of lung cancer; it overcomes many of these criticisms. The survey prospectively studied a general population aged 45-64 years, and the collected data allowed participants from the same household to be identified. The measure of exposure to environmental tobacco was obtained directly from cohabitees and did not rely on self reporting. Data on prevalences of symptoms of respiratory and cardiovascular disease, forced expiratory volume in one second, mortality, and incidence of cancer are all available for this population. The findings reported here update an earlier report; it adds 567 further deaths to the previous findings ${ }^{11}$ and extends the range of baseline measurements to include forced expiratory volume in one second. Confounding variables such as social class, blood pressure, cholesterol concentration, body mass index, and social class have been allowed for in calculating relative risks for passive smokers.

\section{Subjects and methods}

This general population cohort comprises all men and women aged 45-64 years resident in the towns of Renfrew and Paisley in the west of Scotland between 1972 and $1976 .{ }^{12}$ Eligibility was established by a door to door census of all households in the two towns. Everyone who met the age and residency criteria was invited to attend one of 12 temporary centres for a multiphasic cardiorespiratory screening examination. ${ }^{1}$ Between 1972 and 1976, 15399 residents (an 80\% response) completed a standardised self administered questionnaire that included questions on smoking behaviour and was checked by experienced interviewers when subjects attended for screening. Respiratory symptoms were assessed with the Medical Research Council's bronchitis questionnaire. By identifying participants from the same household it was possible to study varying exposures to tobacco smoke in a subsample of 3960 men and 4037 women and to calculate relative risks for a range of cardiorespiratory variables including mortality.

Four groups, in which the index case was aged 45-64 at the time of the survey, were defined based on the index case and on the cohabitees ever or never having smoked.

(1) Control: the index case had never smoked and lived at the same address as another subject who had never smoked. No one else in the household who attended for screening was a smoker or ex-smoker.

(2) Passive smoking: the index case had never smoked and lived at the same address as a subject who had.

(3) Single smoking: the index case was a smoker or ex-smoker and lived at the same address as a subject who had never smoked. No one else in the household who attended for screening was a smoker or exsmoker.

(4) Double smoking: the index case was a smoker or ex-smoker who lived at the same address as a subject who was also a smoker or ex-smoker.

If the index cases were ex-smokers they were classified as single smokers or double smokers depending on whether the cohabitees had never smoked or 
ever smoked. If the cohabitees were ex-smokers the index cases were classified as passive smokers if they had never smoked or as double smokers if they had ever smoked. Thus the controls represent a group whose passive exposure was as low as possible within the constraints of the study design. Results for the two active smoking groups have been included to give some indication of dose-response and provide a perspective for any differences found between the control and passive smoking groups.

A cohabitee was defined as a respondent sharing the same household environment and examined at the same time in the survey as the index case. Some households contained cohabitees of the same sex. Some of the subjects who were examined were above or below the age range eligible for inclusion in the study. These subjects were not analysed as index cases but information on their smoking behaviour as cohabitees was used as the measure of passive exposure for eligible index cases.

Mortality data was obtained from the National Health Service central register and the General Register

TABLE I-Composition of groups exposed to cigarette smoke

\begin{tabular}{lrrr}
\hline & $\begin{array}{c}\text { No(\%) of men } \\
\text { (index cases) }\end{array}$ & $\begin{array}{c}\text { No(\%) of women } \\
\text { (index cases) }\end{array}$ & Total \\
\hline Controls (neither index case nor cohabitee ever smoked) & $428(10 \cdot 8)$ & $489(12 \cdot 1)$ & 917 \\
Passive smoking (only cohabitee ever smoked) & $243(6 \cdot 1)$ & $1295(32 \cdot 1)$ & 1538 \\
Single smoking (only index case ever smoked) & $1420(35 \cdot 9)$ & $331(8 \cdot 2)$ & 1751 \\
Double smoking (both index case and cohabitee ever smoked) & $1869(47 \cdot 2)$ & $1922(47 \cdot 6)$ & 3791 \\
\hline Total & $3960(100)$ & $4037(100)$ & 7997 \\
\hline
\end{tabular}

TABLE II -Social class of men in groups exposed to cigarette smoke. Figures in parentheses are percentages

\begin{tabular}{lcccr}
\hline & \multicolumn{4}{c}{ Exposure group } \\
\cline { 2 - 5 } Social class & Controls & $\begin{array}{c}\text { Passive } \\
\text { smoking }\end{array}$ & $\begin{array}{c}\text { Single } \\
\text { smoking }\end{array}$ & $\begin{array}{c}\text { Double } \\
\text { smoking }\end{array}$ \\
\hline I & $23(5 \cdot 4)$ & $13(5 \cdot 3)$ & $61(4 \cdot 3)$ & $78(4 \cdot 2)$ \\
II & $85(19 \cdot 9)$ & $37(15 \cdot 2)$ & $225(15 \cdot 8)$ & $235(12 \cdot 6)$ \\
III non-manual & $63(14 \cdot 7)$ & $23(9 \cdot 5)$ & $197(13 \cdot 9)$ & $204(10 \cdot 9)$ \\
III manual & $157(36 \cdot 7)$ & $96(39 \cdot 5)$ & $538(37 \cdot 9)$ & $771(41 \cdot 3)$ \\
V & $80(18 \cdot 7)$ & $59(24 \cdot 3)$ & $315(22 \cdot 2)$ & $438(23 \cdot 4)$ \\
Insufficient information & $17(4 \cdot 0)$ & $11(4 \cdot 5)$ & $68(4 \cdot 8)$ & $122(6 \cdot 5)$ \\
\hline Total & $3(0 \cdot 7)$ & $4(1 \cdot 6)$ & $16(1 \cdot 1)$ & $21(1 \cdot 1)$ \\
\hline
\end{tabular}

Office for Scotland. Incidence of cancer was obtained through the cancer registry system and used to verify that the classification on the death certificate was the same as that received by the registry. Data presented are complete to the end of December 1985, an average follow up of $11 \cdot 5$ years.

Prevalences for respiratory and cardiovascular symptoms were standardised for age and sex using the age and sex distribution of the whole cohort as standard. Similarly, mortality was standardised for age and sex using life tables to estimate survival at 11 years of follow up. ${ }^{1+}$

Mean forced expiratory volumes in one second for the four exposure groups were adjusted for age, height, and sex by determining the best fit set of parallel regression models for forced expiratory volume in one second as a linear function of age and height for men and women separately in each group. The mean adjusted forced expiratory volume in one second for each group was then calculated for the average age and height of men and women separately, and a weighted average (corresponding to the proportion of men and women) was computed. Probability values were obtained from the analysis of variance.

Estimates of relative risk and $95 \%$ confidence intervals for passive smokers compared with controls were adjusted for age, sex, social class, diastolic blood pressure, serum cholesterol concentration and body mass index (weight $\left.(\mathrm{kg}) /(\text { height }(\mathrm{m}))^{2} \times 100\right)$ using the logistic regression model ${ }^{15}$ for cardiorespiratory symptoms and Cox's proportional hazards model for mortality. ${ }^{16}$ Levels of significance were derived from the partial likelihood function. ${ }^{17}$ The biomedical data processing programs (BMDP) package was used to compute estimates of risk and levels of probability. ${ }^{18}$

A supplementary questionnaire in two of the 12 centres in which the survey was carried out asked subjects the extent to which they were exposed to cigarette smoke from any other person in the household, irrespective of whether these people were eligible for or attended the survey, and also in their work environment.

\section{Results}

The number of men and women in the four exposure groups is shown in table I. Passive smokers comprised

TABLE III - Smoking habit of cohabitees in passive smoking and double smoking groups. Figures are percentages (numbers)

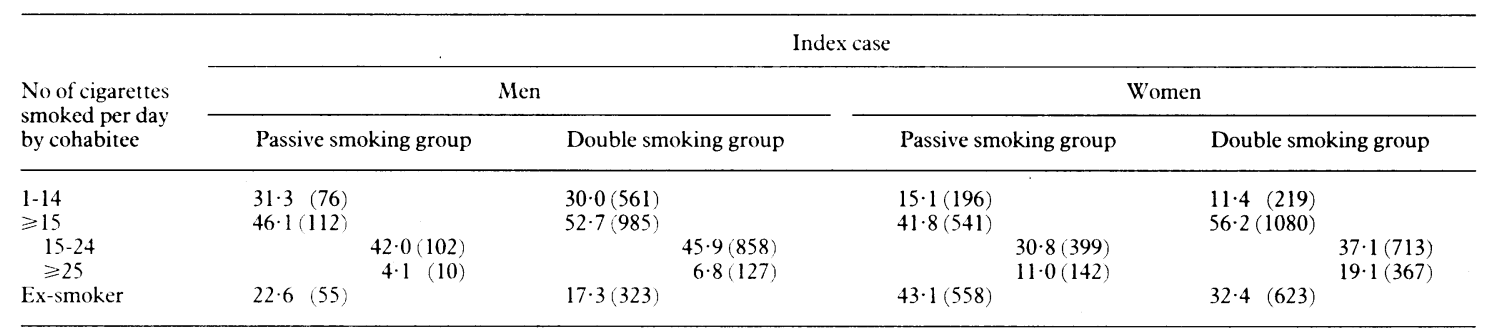

TABLE IV-Age and sex standardised rates of respiratory and cardiovascular symptoms related to exposure to cigarette smoke. Numbers of index cases with symptoms are given in parentheses

\begin{tabular}{|c|c|c|c|c|}
\hline & \multicolumn{4}{|c|}{ Exposure group } \\
\hline & $\begin{array}{l}\text { Controls } \\
(\mathrm{n}=917)\end{array}$ & $\begin{array}{l}\text { Passive smoking } \\
\quad(\mathrm{n}=1538)\end{array}$ & $\begin{array}{l}\text { Single smoking } \\
\quad(\mathrm{n}=1751)\end{array}$ & $\begin{array}{l}\text { Double smoking } \\
\quad(\mathbf{n}=3791)\end{array}$ \\
\hline \multicolumn{5}{|l|}{ Respiratory symptoms: } \\
\hline Infected sputum & $2 \cdot 3(22)$ & $3.3(44)$ & $10 \cdot 5(189)$ & $10 \cdot 5(396)$ \\
\hline Persistent sputum & $7 \cdot 8(72)$ & $9 \cdot 9(122)$ & $28 \cdot 0(541)$ & $28 \cdot 7(1079)$ \\
\hline Dyspnoea & $10 \cdot 1(95)$ & $12 \cdot 2(197)$ & $13 \cdot 4(229)$ & $16 \cdot 6(618)$ \\
\hline Hypersecretion & $5 \cdot 3(48)$ & $6.9(81)$ & $17 \cdot 6(327)$ & $18 \cdot 3(681)$ \\
\hline \multicolumn{5}{|l|}{ Cardiovascular symptoms: } \\
\hline Angina & $4 \cdot 6(43)$ & $4 \cdot 7(74)$ & $7 \cdot 7(165)$ & $9 \cdot 1(334)$ \\
\hline Major abnormality found on electrocardiogram & $1.0(8)$ & $1 \cdot 1$ (13) & $1 \cdot 4(31)$ & $1.5 \quad(49)$ \\
\hline \multicolumn{5}{|l|}{ Mean forced expiratory rate in one second (1): } \\
\hline Unadjusted & $2 \cdot 32$ & $2 \cdot 21$ & $2 \cdot 12$ & $2 \cdot 09$ \\
\hline Adjusted & $2 \cdot 31$ & $2 \cdot 23$ & $2 \cdot 12$ & $2 \cdot 07$ \\
\hline
\end{tabular}


TABLE v-Age and sex adjusted mortality per 10000 per year by category of exposure to cigarette smoke. Figures in parentheses are actual numbers of deaths

\begin{tabular}{lrrrr}
\hline & Controls & $\begin{array}{c}\text { Passive } \\
\text { smoking }\end{array}$ & $\begin{array}{c}\text { Single } \\
\text { smoking }\end{array}$ & $\begin{array}{c}\text { Double } \\
\text { smoking }\end{array}$ \\
\hline All causes & $83 \cdot 1(99)$ & $97 \cdot 4(164)$ & $160 \cdot 0(420)$ & $155 \cdot 6(734)$ \\
Lung cancer & $1 \cdot 6(2)$ & $5 \cdot 0(7)$ & $23 \cdot 2(54)$ & $21 \cdot 4(93)$ \\
Ischaemic heart disease & $27 \cdot 3(30)$ & $47 \cdot 7(54)$ & $61 \cdot 0(171)$ & $60 \cdot 7(260)$ \\
All causes of death related to smoking & $60 \cdot 8(71)$ & $72 \cdot 2(104)$ & $130 \cdot 4(362)$ & $129 \cdot 9(592)$ \\
\hline
\end{tabular}

TABLE VI-Age adjusted prevalence of respiratory and cardiovascular symptoms and age standardised mortality per 10000 per year for women in control and passive smoking groups. Figures in parentheses are numbers of actual cases

\begin{tabular}{|c|c|c|c|}
\hline & \multirow[b]{2}{*}{$\begin{array}{l}\text { Controls } \\
(n=489)\end{array}$} & \multicolumn{2}{|c|}{ Passive smokers } \\
\hline & & $\begin{array}{l}\text { Low exposure } \\
\quad(n=754)\end{array}$ & $\begin{array}{l}\text { High exposure } \\
\quad(\mathrm{n}=541)\end{array}$ \\
\hline & revalence & & \\
\hline \multicolumn{4}{|l|}{ Respiratory symptoms: } \\
\hline Infected sputum & $2 \cdot 1(10)$ & $2 \cdot 4(18)$ & $3 \cdot 1(17)$ \\
\hline Persistent sputum & $6 \cdot 4(31)$ & $5 \cdot 8(45)$ & $8 \cdot 6(46)$ \\
\hline Dyspnoea & $12 \cdot 7(60)$ & $11 \cdot 2(84)$ & $16 \cdot 2(88)$ \\
\hline Hypersecretion & $4 \cdot 1(19)$ & $3.8(29)$ & $5 \cdot 7(30)$ \\
\hline \multicolumn{4}{|l|}{ Cardiovascular symptoms: } \\
\hline Angina & $3 \cdot 6(17)$ & $4 \cdot 1(32)$ & $5 \cdot 8(31)$ \\
\hline \multirow[t]{2}{*}{ Major abnormality found on electrocardiogram } & $0.4(2)$ & $1 \cdot 1(8)$ & $0.5(2)$ \\
\hline & Mortality & & \\
\hline All causes & $58 \cdot 3(32)$ & $64 \cdot 6(70)$ & $87 \cdot 8(54)$ \\
\hline Lung cancer & $3 \cdot 2(1)$ & $2 \cdot 5 \quad(2)$ & $5 \cdot 7(3)$ \\
\hline Ischaemic heart disease & $6.8(3)$ & $14 \cdot 2(14)$ & $28 \cdot 0(16)$ \\
\hline All causes of death related to smoking & $34 \cdot 9(17)$ & $35 \cdot 2(39)$ & $47 \cdot 3(30)$ \\
\hline
\end{tabular}

$6 \cdot 1 \%(243 / 3960)$ of men and $32 \cdot 1 \%(1295 / 4037)$ of women. Of the cohabitees, $91 \cdot 6 \%(7325)$ were of the opposite sex. The composition of the groups by social class is shown in table II.

The extent of passive exposure experienced by passive smokers in relation to subjects in the double smoking group is shown in table III. In all, $46 \cdot 1 \%(112)$ men and $41 \cdot 8 \%$ (541) women in the passive smoking group lived in households where the cohabitee was smoking 15 or more cigarettes a day. This compared with $52 \cdot 7 \%(985)$ men and $56 \cdot 2 \%(1080)$ women in the double smoking group. Ex-smokers were more common in households in which the index case had never smoked.

The prevalence of signs and symptoms for the four exposure groups is shown in table IV. For each of the four respiratory measures (infected sputum, persistent sputum, dyspnoea, and hypersecretion) the rates in the control group were lower than those in the passive smoking group and considerably lower than in the single and double smoking groups. The rates for angina and major abnormalities found on electrocardiography were similar in the control and passive smoking groups and lower than in the active smoking groups.

Mean forced expiratory volumes in one second adjusted for sex, age, and height were significantly higher $(p<0.01)$ in controls than in those passively exposed to cigarette smoke and were significantly higher than among active smokers.

Mortality adjusted for age and sex in the four groups is presented in table $\mathrm{V}$. Total mortality was higher among passive smokers than controls. This was reflected in the category of all causes of death related to smoking and was highest for ischaemic heart disease. Lung cancer mortality was higher among passive smokers than controls, but the number of deaths involved was small.

The supplementary questionnaire on exposure to cigarette smoke at home and work allowed a check to be made of the smoking habits of other household members who were not part of the survey. A regular smoker living in the same household was reported by $5 \%(2 / 44)$ of controls compared with $69 \%(27 / 39)$ of passive smokers. Of women, $21 \%(13 / 62)$ of controls lived in households with a regular smoker compared with $63 \%(125 / 197)$ of passive smokers.

Women reported that most of their passive exposure was at home rather than at work, which suggested that they were the appropriate group in which to examine whether there was a dose-response relation. A high exposure passive smoking group was therefore defined as women whose cohabitee was smoking 15 or more cigarettes daily, and the remaining female passive smokers were defined as a low exposure group. Table VI presents the age standardised rates for respiratory and cardiovascular symptoms and mortality for the control and the low and high exposure passive smoking groups. For each of the four respiratory symptoms the highly exposed passive smokers had rates that were higher than those in passive smokers whose exposure was low and those in the controls. There were no consistent differences between the low passive exposure group and the controls. A similar pattern was found for angina but not for major abnormalities detected by electrocardiography.

The adjusted forced expiratory volume at one second was significantly lower in passive smokers with high exposure compared with those with low exposure (mean $1.831 v 1.891 ; \mathrm{p}<0.05$ ). No significant difference was found between passive smokers with low exposure and controls $(1.891 v 1.881)$. Age adjusted mortality was increased for the passive smokers with high exposure compared with low and with controls for all cause mortality, all cause mortality related to smoking, ischaemic heart disease, and lung cancer.

Table VII shows the adjusted relative risks for passive and active smokers compared with controls. For each variable the relative risk associated with passive smoking was $>1 \cdot 0$. The confidence interval included 1.0 except for ischaemic heart disease, for which the estimate of risk was significantly different from unity $(\mathrm{p}=0 \cdot 008)$.

Table VIII shows the relative risks for double smokers compared with single smokers after additional adjustment for quantity smoked. Dyspnoea was signi-

TABLE VII-Relative risks associated with passive smoking adjusted for age, sex, and social class and for cardiovascular variables, diastolic blood pressure, serum cholesterol concentration, and body mass index

\begin{tabular}{|c|c|c|c|c|}
\hline & $\begin{array}{l}\text { Relative risk } \\
\text { (passive smokers compared } \\
\text { with controls) }\end{array}$ & $\begin{array}{l}95 \% \text { Confidence } \\
\text { interval }\end{array}$ & p Value & $\begin{array}{l}\text { Relative risk } \\
\text { (active smokers compared } \\
\text { with controls) }\end{array}$ \\
\hline \multicolumn{5}{|l|}{ Respiratory symptoms: } \\
\hline Infected sputum & $1 \cdot 34$ & 0.76 to 2.36 & $0 \cdot 3$ & 4.53 \\
\hline Persistent sputum & $1 \cdot 19$ & 0.85 to 1.67 & $0 \cdot 3$ & $4 \cdot 49$ \\
\hline Dyspnoea & 1.09 & 0.82 to 1.45 & $0 \cdot 5$ & $1 \cdot 60$ \\
\hline Hypersecretion & $1 \cdot 21$ & 0.81 to 1.82 & $0 \cdot 3$ & $3 \cdot 77$ \\
\hline \multicolumn{5}{|l|}{ Cardiovascular symptoms: } \\
\hline Angina & $1 \cdot 11$ & 0.73 to 1.70 & $0 \cdot 6$ & 1.89 \\
\hline Major abnormalities found on electrocardiogram & $1 \cdot 27$ & 0.48 to 3.35 & $0 \cdot 6$ & 1.51 \\
\hline \multicolumn{5}{|l|}{$\begin{array}{l}\text { Mortality: } \\
\text { Plo }\end{array}$} \\
\hline All causes & $1 \cdot 27$ & 0.95 to 1.70 & $0 \cdot 10$ & $2 \cdot 07$ \\
\hline All causes of death related to smoking & $1 \cdot 30$ & 0.91 to 1.85 & $0 \cdot 15$ & $2 \cdot 33$ \\
\hline Ischaemic heart disease & $2 \cdot 01$ & 1.21 to 3.35 & 0.008 & $2 \cdot 27$ \\
\hline Lung cancer & $2 \cdot 41$ & 0.45 to 12.83 & $0 \cdot 3$ & $10 \cdot 64$ \\
\hline
\end{tabular}


TABLE VIII-Relative risks in double smokers compared with single smokers, adjusted for age, sex, amount smoked, and social class and for cardiovascular variables, diastolic blood pressure, serum cholesterol concentration, and body mass index

\begin{tabular}{|c|c|c|c|}
\hline & Relative risk & $\begin{array}{c}95 \% \text { Confidence } \\
\text { interval }\end{array}$ & p Value \\
\hline \multicolumn{4}{|l|}{ Respiratory symptoms: } \\
\hline Infected sputum & 0.96 & 0.79 to $1 \cdot 16$ & $0 \cdot 65$ \\
\hline Persistent sputum & 1.06 & 0.92 to 1.21 & $0 \cdot 45$ \\
\hline Dispnoea & $1 \cdot 25$ & 1.05 to 1.49 & 0.02 \\
\hline Hypersecretion & $1 \cdot 02$ & 0.87 to 1.20 & 0.75 \\
\hline \multicolumn{4}{|l|}{ Cardiovascular symptoms: } \\
\hline Angina & $1 \cdot 17$ & 0.95 to 1.44 & $0 \cdot 15$ \\
\hline Major abnormalities found on electrocardiogram & $1 \cdot 11$ & 0.68 to 1.79 & 0.65 \\
\hline \multicolumn{4}{|l|}{$\begin{array}{l}\text { Mortality: } \\
\end{array}$} \\
\hline All causes & $1 \cdot 01$ & 0.87 to $1 \cdot 18$ & $0 \cdot 9$ \\
\hline All causes of death related to smoking & $0 \cdot 99$ & 0.84 to $1 \cdot 16$ & $0 \cdot 9$ \\
\hline Ischacmic heart disease & 0.89 & $0 \cdot 72$ to $1 \cdot 11$ & $0 \cdot 3$ \\
\hline Lung cancer & $1 \cdot 13$ & 0.79 to 1.63 & 0.5 \\
\hline
\end{tabular}

ficantly more common among double smokers $(\mathrm{p}=$ 0.02 ), and though none of the other variables was significant, six had risks $>1 \cdot 0$.

\section{Discussion}

Whether inhaling other people's tobacco smoke is a risk factor for lung cancer and other diseases related to smoking is now under serious scientific consideration. Studies of the concentrations of cotinine in the urine and saliva of passive smokers suggest that the dose received may be equivalent to smoking up to three cigarettes a day. ${ }^{19}$ Though sidestream smoke contains different proportions of chemical constituents than does mainstream smoke and the same dose received passively might not translate directly to the same risk as in active smokers, the risks expected for passive smokers will probably be of a similar magnitude to those found in active smokers of up to three cigarettes daily; consequently, only very large studies will have sufficient power to detect such risks. A meta-analysis is currently the only way to establish precise estimates of risk, and it is essential that all studies are included.

This paper updates a previous publication" with mortality now extended to an average follow up time of 11.5 years and the control and passive smoking groups redefined to exclude those who smoked only pipes or cigars and those who smoked cigarettes irregularly. The original questionnaire in its coded form did not distinguish pipe and cigar smokers and those who smoked fewer than five cigarettes a day from nonsmokers. Written information on the questionnaires allowed this to be clarified, and these additional data were added to the computer files.

The sample size in this study does not provide sufficient statistical power to detect risks of the magnitude expected. Thus the lack of significance should not be the sole criterion of whether a genuine effect may be present. Several findings should be borne in mind when interpreting these results. Firstly, for each of the 10 measures examined, from respiratory symptoms to causes of mortality, the relative risk was consistently larger than unity. This remained so after adjusting for intervening risk factors such as age, sex, social class, blood pressure, cholesterol concentration, and body mass index. Secondly, the one measure for which sufficient statistical power was available - that is, forced expiratory volume in one second-gave a significant result. Thirdly, when a group of passive smokers with high exposure was defined there was an increase in the dose-response relation for nine of the 10 variables. Fourthly, in comparison with the relative risks found for the two active smoking groups, each increased risk was biologically plausible, with the possible exception of that for ischaemic heart disease.

The findings for respiratory symptoms are similar to those of other studies: a decreased forced expiratory volume in one second in passive smokers has been found previously,,$^{20}$ and the risks for lipng cancer are consistent with those in the overview by Wald et al. Few data relate passive smoking to cardiovascular disease, but a relative risk as high as $2 \cdot 2$ for mortality from ischaemic heart disease in passive smokers has been quoted. ${ }^{7}$ Our risk of $2 \cdot 0$ seems large in comparison with that found for active smokers, and the possibility that chance has inflated this risk cannot be excluded, but as the lower $95 \%$ confidence limit for the relative risk is greater than one it would appear that chance alone is not responsible for the excess.

When investigating risks close to unity it is important to consider the effect of potential biases. Biases may operate at the time data are collected. Between 1972 and 1976, however, passive smoking was not an issue. Subjects reported their own smoking habits and no self reporting of passive exposure was undertaken. It was not until 1983 that subjects within the same household were linked, and this was carried out without any reference to the measures of outcome examined subsequently.

There is no direct measure available to prove that the passive smokers received a higher environmental dose of tobacco smoke than the controls, but in the supplementary questionnaire that covered the smoking habits of household members irrespective of whether they attended the original survey only $5 \%$ of controls said that there was a current smoker in the household, compared with $63 \%$ of passive smokers. Greater exposure to tobacco smoke at work supported the idea that passive smokers were more likely than controls to be in contact with environmental tobacco smoke outside the home. This was measured by Wald and Ritchie, ${ }^{21}$ who showed that non-smoking husbands of smoking wives had higher urinary cotinine concentrations than non-smoking husbands of non-smoking wives. Our definition of categories of exposure is comparable with that of other studies and would seem to identify groups with different mean levels of passive exposure. The high level of heavy smoking in our cohort $^{22}$ might also indicate that this difference is greater than that found in other studies.

The problem of smokers deliberately classifying themselves as non-smokers ${ }^{23}$ is a far less serious bias in cohort studies than in case-control studies, because at the interview stage there is no indication which subjects will subsequently die. The likelihood of differential misclassification rates - that is, higher in the passive smoking than in the control group-is debatable as this implies that someone in the double smoking group is more likely to pretend to be a non-smoker than someone in the single smoking group. When the cohabitee is a smoker the reverse may be more likely to be true.

It has been suggested that non-smokers who marry smokers may be different from non-smokers who marry non-smokers. ${ }^{24} \mathrm{~A}$ higher proportion of passive smokers were in social classes III manual, IV, and V, but no differences were found for other possible risk factors such as occupation, raised blood pressure, cholesterol concentration, or body mass index. In any case the final analysis, which estimated the relative risks, adjusted for each of these factors.

The effect of passive smoking on those who already smoke is far harder to isolate. The dose received by active smokers from smoking ranges widely, ${ }^{1925}$ and adding a small extra component due to passive exposure may not lead to much of a difference in mean doses for double smokers compared with single smokers. Hence, the increased risk for double smokers relative to single smokers may be substantially less than that for passive smokers relative to controls. Thus the statistical power of a single study is an important consideration and in the absence of other published data on this aspect it is difficult to interpret our results 
for the effects of passive smoking on smokers. Therefore the main emphasis of this paper is an estimation of the risks of passive smoking in lifelong non-smokers; data are presented for the active smoking groups to provide an estimate of dose-response.

Our results are based on a general population cohort study carried out in an area with a high level of diseases related to smoking. A consistent increase in risk was observed in passive smokers for each of the 10 variables measured covering respiratory symptoms, forced expiratory volume in one second, cardiovascular symptoms, and subsequent mortality, including lung cancer and ischaemic heart disease. A dose-response relation was seen, and the risks were biologically plausible in relation to the size of the risks found for the active smokers. These three factors taken together increase our concern that exposure to other people's tobacco smoke cannot be regarded as a safe involuntary practice.

1 Colley JRT, Holland WW, Corkhill RT. Influence of passive smoking and parental phlegm on pneumonia and bronchitis in early childhood. Lancet 1974;ii: 1031-4.

2 Weiss ST, Tager IB, Speizer FE, Rosner B. Persistent wheeze-its relation to respiratory illness, cigarette smoking, and level of pulmonary function in a respiratory illness, cigarette smoking, and level of pulmonary func

3 White JR, Froeb HF. Small airways dysfunction in non-smokers chronically exposed to tobacco smoke. $N$ Engl F Med 1980;302:720-3.

4 Kauffmann F, Tessier JF, Oriol W. Adult passive smokers in the home environment: a risk factor for chronic airflow limitation. Am F Epidemiol 1983;117:269-80

Lebowitz MD. Influence of passive smoking on pulmonary function: a survey Prev Med 1984;13:645-55.

6 Wald NJ, Nanchalal K, Thompson SG, Cuckle HS. Does breathing other people's tobacco smoke cause lung cancer? Br Med $\mathcal{f}$ 1986;293:1217-22.

7 Garland C, Barrett-Conner E, Suarez L, et al. Effects of passive smoking on ischaemic heart disease mortality of non-smokers: a prospective study. Am f Epidemiol 1985;121:645-50.
8 Hirayama T. Passive smoking: a new target of epidemiology. Tokai $f$ Exp Clin Med 1985;10:287-93.

9 Svendsen KH, Kuller LH, Martin MJ, Ockene JK. Effects of passive smoking in the multiple risk factor intervention trial. Am $\mathcal{F}$ Epidemiol 1987;126: $783-95$

10 US Department of Health and Human Services. Respiratory effects of involuntary smoke exposure: epidemiologic studies. Report of a workshop, 1-3 Mav 1983. Bethesda, Maryland: National Institutes of Health, 1983.

11 Gillis CR, Hole DJ, Hawthorne VM, Boyle P. The effect of environmental tobacco smoke in two urban communities in the west of Scotland. Eur $\mathcal{F}$ tobacco smoke in two urban commu
Respir Dis 1984;65 (suppl 133):121-6.

12 Hawthorne VM, Gillis CR, Maclean DS. Monitoring health in Scotland. Int $f$ Epidemiol 1975;1:369-74.

13 Hawthorne VM, Greaves DA, Beevers DG. Blood pressure in a Scottish town. BrMed F 1974;1:600-3.

14 Kaplan EL, Meier P. Nonparametric estimation from incomplete observations. fournal of the American Statistical Association 1958;53:457-81.

15 Cox DR. The analysis of binary data. London: Methuen, 1970.

16 Cox DR. Regression models and life tables. Fournal of the Royal Statistical Society $(B)$ 1972;34:187-220.

17 Cox DR. Partial likelihood. Biometrika 1975;62:269-76.

8 Dixon WJ, Brown MB, Engelman L, et al. Biomedical data processing programs. Statistical software 1985. Los Angeles: University of Calfornia Press, 1985.

19 Matsukura S, Taminato $T$, Kitano $N$, et al. Effects of environmental tobacco smoke on urinary cotinine excretion in non-smokers. N Engl $\mathcal{F} \mathrm{Med}$ 1984;311:828-32.

20 Hoffmann D, Brunnemann KD, Adams JD, et al. Indoor pollution by tobacco smoke: model studies on the uptake by non-smokers. In: Berglund B, ed. Indoor air, radon, passive smoking, particulates and housing epidemiology. Indoor air, radon, passive smoking, particulates and housing epidemiology.
Vol 2. Stockholm: Swedish Council for Building Research, 1984:313-8. Vol 2. Stockholm: Swedish Council for Building Research, $1984: 313-8$.
(Proceedings of the 3rd international conference on indoor air quality and climate, suppl D17.

21 Wald N, Ritchie C. Validation of studies on lung cancer in non-smokers married to smokers. Lancet 1984;i: 1067 .

22 Gillis CR, Hole DJ, Hawthorne VM. Cigarette smoking and male lung cancer in an area of very high incidence. II. Report of a general population cohor study in the West of Scotland. F Epidemiol Community Health 1988;42:44-8.

23 Lee PN. Misclassification as a factor in passive smoking risk. Lance 1986;ii:867.

24 Burch PRJ. Passive smoking in adulthood and cancer risk. Am $\mathcal{f}$ Epidemiol $1986 ; 123: 368-9$

25 Wald NJ, Boreham J, Bailey A, Ritchie C, Haddow JE, Knight G. Urinary cotinine as a marker of breathing other people's tobacco smoke. Lance 1984;i:230-1.

\title{
Carbohydrate deficient transferrin: a marker for alcohol abuse
}

\author{
A Kapur, G Wild, A Milford-Ward, D R Triger
}

\section{Abstract}

Objective-To assess the value of serum carbohydrate deficient transferrin as detected by isoelectric focusing on agarose as an indicator of alcohol abuse.

Design-Coded analysis of serum samples taken from patients with carefully defined alcohol intake both with and without liver disease. Comparison of carbohydrate deficient transferrin with standard laboratory tests for alcohol abuse.

Setting - A teaching hospital unit with an interest in general medicine and liver disease.

Patients-22 "Self confessed" alcoholics admitting to a daily alcohol intake of at least $80 \mathrm{~g}$ for a minimum of three weeks; 15 of the 22 self confessed alcoholics admitted to hospital for alcohol withdrawal; 68 patients with alcoholic liver disease confirmed by biopsy attending outpatient clinics and claiming to be drinking less than $50 \mathrm{~g}$ alcohol daily; 47 patients with non-alcoholic liver disorders confirmed by biopsy; and 38 patients with disorders other than of the liver and no evidence of excessive alcohol consumption.

Intervention-Serial studies performed on the 15 patients undergoing alcohol withdrawal in hospital.

Main outcome measure-Determination of relative value of techniques for detecting alcohol abuse.

Results-Carbohydrate deficient transferrin was detected in 19 of the $22(86 \%)$ self confessed alcohol abusers, none of the 47 patients with non-alcoholic liver disease, and one of the $38(3 \%)$ controls. Withdrawal of alcohol led to the disappearance of carbohydrate deficient transferrin at a variable rate, though in some subjects it remained detectable for up to 15 days. Carbohydrate deficient transferrin was considerably superior to the currently available conventional markers for alcohol abuse.

Conclusion-As the technique is fairly simple, sensitive, and inexpensive we suggest that it may be valuable in detecting alcohol abuse.

\section{Introduction}

The medical and social consequences of alcohol abuse are major problems throughout the world. Although many people readily acknowledge the extent of their alcohol consumption, others attempt to conceal it, and we lack reliable objective means of identifying surreptitious alcohol consumption. Currently available laboratory markers have considerable limitations, being insensitive, non-specific, or dependent on liver damage. The mean corpuscular volume rises in patients with thyroid disease, folic acid deficiency, and liver disease, ${ }^{1}$ whereas serum $\gamma$-glutamyltransferase activity is affected by drugs that induce microsomal enzymes as well as rising in all forms of obstructive liver damage. ${ }^{2}$ Serum aspartate aminotransferase activity is more commonly raised in alcoholics than alanine aminotransferase activity is, and whereas a ratio of aspartate to alanine aminotransferase activity of greater than 2:1 is strongly suggestive of alcoholic liver diseas $^{3}$ this is of little value in subjects in whom the 